\title{
Ion exchanged vermiculites with lower expansion onset temperatures
}

\author{
Hermínio F. Muiambo ${ }^{\mathrm{a}, 1}$, Walter W. Focke ${ }^{\mathrm{b}, *}$ \\ ${ }^{a}$ Institute of Applied Materials, Department of Chemistry, University of Pretoria, Lynnwood Road, \\ Pretoria 0002, South Africa. \\ ${ }^{\mathrm{b}}$ Institute of Applied Materials, Department of Chemical Engineering, University of Pretoria, \\ Lynnwood Road, Pretoria 0002, South Africa. \\ "Correponding author. Tel.: +27 12420 3728; FAX: +27 12420 2516. E-mail address: \\ walter.focke@up.ac.za \\ ${ }^{1}$ Permanent address: Department of Chemistry, Eduardo Mondlane University, P.O. Box 257, \\ Maputo, Mozambique.E-mail address: hmuiambo@uem.mz
}

\begin{abstract}
South African Palabora vermiculite was modified by ion exchange with ammonium and selected alkali metal and alkaline earth metal ions. In the exchanged vermiculite with ammonium ions, it was found that ammonia and water were the blowing agents and they were simultaneously released during thermal degradation. In the increasing ionic potential series: $\mathrm{Na}, \mathrm{Ba}, \mathrm{Ca}$ and $\mathrm{Mg}$, it was found that the onset expansion temperature also increased dramatically. Exchange with relatively low ionic potential species, namely sodium, potassium and ammonium, lowered the exfoliation onset temperature of vermiculite to below $300{ }^{\circ} \mathrm{C}$.
\end{abstract}

Keywords: Vermiculite; Ion exchange; Exfoliation; Interstratification; Thermal Analysis.

Research highlights: > Ore vermiculite was modified by ion exchange with ammonium and selected alkali metal and alkaline earth metal ions. > Ion exchange of vermiculite with relatively low ionic potential cations lowered the exfoliation onset temperature.

Running head title: Vermiculites with lower expansion temperatures 


\section{Introduction}

Clay minerals are attracting increasing interest in nanoscience and nanotechnology due to the dramatic effect that they can have on materials, even at low dosage levels. Such clay applications include nanocomposites, catalysts, adsorbents, sensors, nuclear waste storage, antibacterials, pharmaceuticals, pesticide carriers, among others [1-4].

In the interstratified or mixed-layer vermiculite from Palabora, the individual flakes are made up of elementary layers of two types: vermiculite and biotite. Unlike the potassium cations in biotite, the hydrated interlayer ions (usually magnesium ions) in the vermiculite layers are easily exchanged [5-9]. Palabora vermiculite, like other commercial types, shows considerable variability in both composition and cation exchange capacity (CEC). This is attributed to differences in the composition of the original parent mica and the degree of progress in the chemical changes induced by weathering $[6,10]$.

In intumescent fire barriers applications it is desirable that the vermiculite exfoliates at relatively lower temperatures [11-15].

Ion exchange is a reversible diffusion process of stoichiometrical substitution of the ions held electrostatically on the surface of the clay mineral and those in a solution phase $[1,16-$ 18]. Several authors [19-21] in their studies on ion exchanged vermiculites noticed that Mgvermiculite retains coordinated water more powerfully at comparable elevated temperatures than other vermiculites. This is due to three combined effects: (1) high ionic potential; (2) stronger polarizing effect; and (3) high covalent character [19]. These results were later confirmed and elaborated by [20-22].

Some ion exchanged vermiculites, with less well defined water layer hydration states (WLHS), are less thermally stable than Mg-vermiculite [23]. Compared to pure vermiculite, vermiculite-mica interstratified materials feature higher expansion ratios with the thermal exfoliation also commencing at lower temperatures [21, 24-27]. Additionally, this modified and interstratified vermiculite is amenable to produce a durable exfoliated material [10]. 


\section{$<$ Insert Table 1>}

The ionic potential is defined as the ratio of the ion's electric charge to its radius. It gives an idea of the strength of the ionic bond that can be formed by the cation and the extent of hydration.

Cations with high ionic potential possess high selectivity coefficients. As a result they are able to create a richer interlayer hydration and consequent better enlargement of the interlayer space [28-32].

Determined standard free energies $\left(\Delta \mathrm{G}^{\circ}\right)[28,33]$ suggest the following affinity of alkali and alkaline metal ions to vermiculite layers:

$$
\mathrm{Na}^{+}<\mathrm{Ba}^{2+} \sim \mathrm{Ca}^{2+}<\mathrm{Mg}^{2+}<\mathrm{K}^{+}
$$

Vermiculite selectivity, in the above series, is determined mostly by the entropy increase rather than enthalpy change since both enthalpy and entropy are positive during the ion exchange $[28,33]$. For instance, vermiculite's preference for divalent cations is mainly due to increase in the (configurational) entropy during replacement of monovalent cations by corresponding half-divalent cations [28].

Water bound to the interlayer cations in clay minerals like vermiculite and montmorillonite is arranged in a series of layers, i.e. water layer hydration states (WLHS). These WLHS define the basal reflection and are intrinsically related to the interlayer cation(s), relative humidity and temperature $[26,31,34,35]$. In natural biotite (vermiculite parent mica) the interlayer ions are potassium and the interlayer space contains no water (0WLHS). By contrast, pure vermiculite (Mg-vermiculite) contains the equivalent of up to two sheets of interlayer water (2-WLHS) $[3,34,36]$.

During dehydration, initially there is release of water from external surfaces and mesopores (unbound water), then the water of hydration (bound with the interlayer cation) and finally the water derived from dehydroxylation (combination of surface clay hydroxyl groups) 
[3]. The dehydration and/or rehydration of vermiculite is, to a certain extent, a reversible process $[1,8]$. It progresses stepwise during elimination and/or accumulation of one or several water layers structures, with some overlap, accompanied by a change in the d-spacing $[3,35$, 37]. Previous studies have shown that during thermal dehydration of vermiculite there is no destruction of the crystals: water molecules are released by interlayer diffusion and escape through the cracks $[16,26,28,38]$. Exposing vermiculite to a vacuum causes rapid dehydration. Below $120{ }^{\circ} \mathrm{C}$ the vacuum dehydration is arrested at a 1-WLHS and under vacuum conditions the exfoliation is not dependent on the presence of water above $120{ }^{\circ} \mathrm{C}$ [26].

Exfoliated vermiculite is of industrial interest because it is incombustible, lightweight and shows excellent absorption, thermal protecting and sound insulation properties $[3,9,12,39$ 41]. Vermiculite, with its layered structure and surface characteristics, is utilised in products such as intumescent coatings and gaskets, for the treatment of toxic waste and air-freight packaging of hazardous goods [3, 42].

Since expanded vermiculite is able to retain liquids and gases better than natural soils it is being used in agriculture and animal feeds as an absorbent of water, air and other fluid plant and animal nutrients, and as a filler and carrier for powdered fertilizers and animal nutrients $[9,39,42]$. Exfoliated vermiculite is used in the friction brake linings market [42].

In some applications, notably intumescent fire barriers, it is desirable that the exfoliation of vermiculite should occur at intermediate temperatures, i.e. in the range $200{ }^{\circ} \mathrm{C}$ to $350{ }^{\circ} \mathrm{C}$. Flame retardant compositions have also been proposed that rely on vermiculite expansion properties [11]. However, neat vermiculite expansion occurs at temperatures well above the melting or decomposition temperatures of common polymers.

It was the aim of the present study to lower the onset expansion temperature of Palabora vermiculite to temperatures in the range $200{ }^{\circ} \mathrm{C}$ to $350{ }^{\circ} \mathrm{C}$. Since the surface morphology and 
the properties of vermiculites are closely related to the nature of the interlayer cation [43], ion exchange of original interlayer cations was performed, through room-temperature treatment of Palabora vermiculite.

\section{Experimental: starting materials and techniques}

Mandoval Vermiculite supplied the micron $(0.5 \mathrm{~mm})$ samples of Palabora material. All metal chlorides and ammonium salts were obtained from Merck Chemicals.

Previous kinetic studies have already shown a very slow rate of exchange in similar vermiculites due to the high layer charge density [33, 44, 45]. All experiments were run at the $\mathrm{pH}$ of the salt solution and it was not controlled accurately since the exchange rate is not affected by the $\mathrm{pH}$ in the range of 4 to 9 [28].

The ion exchange by ammonium, alkali metal and alkaline earth metal ions was carried out using a Labex SPO-MP15 orbital shaker for exactly 15 days at room temperature. The frequency of the shaker was adjusted to $200 \mathrm{rpm}$ (rotations per minute). For these experiments, $50 \mathrm{~g}$ of vermiculite were weighed out and enough salt was added to prepare 250

$\mathrm{ml}$ of saturated salt solution: vermiculite selectivity rises with increase of the preferred ion loading $[7,28]$. The ion-exchanged vermiculites were washed thoroughly with distilled water until all chloride anions were quantitatively removed. This was checked by reacting an aliquot of supernatant solution with $0.1 \mathrm{M} \mathrm{AgNO}_{3}$.

The chemical composition of the ion-exchanged vermiculites was determined by X-ray fluorescence (XRF). Thermogravimetry (TG) was performed by the dynamic method on a Mettler Toledo A851 TGA/SDTA instrument. Thermal expansion measurements (TMA) were conducted on a TA instruments Q400 Thermo Mechanical Analyzer. X-ray diffraction (XRD) data were obtained on a BRUKER D8 Advance diffractometer instrument. Fourier-Transform 
Infrared Spectroscopy (FTIR) spectra were recorded using a Perkin Elmer Spectrum RX FTIR.

Detailed descriptions of all the above-mentioned techniques are reported in a previous study [15].

\section{Results and discussion}

The XRF results emphasize the fact that Palabora vermiculite is not pure because the content of potassium, expressed as $\mathrm{K}_{2} \mathrm{O}$, exceeds $0.35 \%[27,33]$.

Several authors $[9,29,30,46,47]$ also found that Palabora vermiculite has, comparatively, an unusually high level of iron. These iron ions (and also aluminium ions) are the main isomorphous substitutes for magnesium in the octahedral sites and also as considerable silica replacements in the tetrahedral sites [46].

Modified vermiculites showed an expected increase in the content of the exchange cations. This confirmed the success of the ion exchange process. However some discrepancies were also observed due to the heterogeneity of the samples (irregularly interstratified naturally occurring material) and the presence of impurities such as apatite, $\mathrm{Ca}_{3}\left(\mathrm{PO}_{4}\right)_{2}$, and $\mathrm{K}$ mica as separated phases. According to Table 2, Ba-vermiculite showed the most noticeable change in chemical composition. Expressed in terms of $\mathrm{BaO}$, it increased by almost $4 \%$, compared to neat vermiculite. This is in agreement with previous findings that note the high affinity of barium ions for the surface of this clay mineral $[48,49]$.

By contrast Mg-vermiculite did not show substantial compositional changes. This was expected due to the fact that neat vermiculite is composed mainly of magnesium ions as exchangeable cations.

$<$ Insert Table 2> 


$$
\begin{aligned}
& 0.60\left(\mathrm{Mg}_{2.60} F e_{0.60}^{2+}\right)\left[\mathrm{Si}_{3.2} A l_{0.78} F e_{0.02}^{3+}\right] \mathrm{O}_{10}(\mathrm{OH})_{2} \mathrm{~K}_{0.49}^{+} \\
& +0.40\left(\mathrm{Mg}_{2.60} F e_{0.60}^{2+}\right)\left[\mathrm{Si}_{3.2} \mathrm{Al}_{0.78} \mathrm{Fe}_{0.02}^{3+}\right] \mathrm{O}_{10}(\mathrm{OH})_{2} \mathrm{Mg}_{0.20}^{2+} . n \mathrm{H}_{2} \mathrm{O}
\end{aligned}
$$

Scheme I: Structural formula of neat-vermiculite consistent with the XRF data.

Ion exchanged vermiculites show a multi-stage thermal decomposition. $\mathrm{Mg}$-vermiculite exhibits relatively (well known) stable intermediates, while $\mathrm{NH}_{4}$-vermiculite shows extensive dehydration in the second stage (Fig. 1). $\mathrm{NH}_{4}$-vermiculite shows a decomposition that resembles the recoil effect [50] and an overall total mass loss close to $18 \%$, whereas the other ion exchanged vermiculites show mass losses below 10\%. The higher mass loss in $\mathrm{NH}_{4}-$ vermiculite is a result of the release of both water and ammonia $\left(\mathrm{NH}_{3(\mathrm{~g})}\right)[22,43,51]$

In the range of $250-520^{\circ} \mathrm{C}$, the expansion temperature of vermiculites, only about $1.0 \%$ of mass is lost for all vermiculites ion exchanged with metal ions. However, in the same interval, $\mathrm{NH}_{4}$-vermiculite shows mass losses of around $7.1 \%$, for the same reasons mentioned above (Fig. 2).

$<$ Insert Fig. 2>

Between $520{ }^{\circ} \mathrm{C}$ and $1000{ }^{\circ} \mathrm{C}$ dehydroxylation of all samples occurred. Again $\mathrm{NH}_{4}-$ vermiculite showed comparatively high mass losses. This behaviour is attributed to the release of both ammonia (Scheme II) and water due to the expected vermiculite dehydroxylation (Scheme III) [22, 43, 51].

$$
[V E R] N H_{4(a q)}^{+} \rightarrow[V E R] H_{(a q)}^{+}+N H_{3(g)}
$$

Scheme II: Thermal decomposition of ammonium ions in vermiculite

$$
[V E R] 2 O H_{(a q)}^{-} \rightarrow[\operatorname{VER}] O_{(a q)}^{2-}+H_{2} O_{(g)}
$$

Scheme III: Dehydroxylation of vermiculite 
A supplementary water quantity, resulting from the combination of hydrogen ions released during ammonia liberation and hydroxyl groups from the vermiculite surface (Scheme IV), is contributed during thermal decomposition of $\mathrm{NH}_{4}$-vermiculite [43, 51].

$$
[V E R] H_{(a q)}^{+}+[V E R] O H_{(a q)}^{-} \rightarrow 2[V E R]+H_{2} O_{(g)}
$$

Scheme IV: Dehydroxylation of vermiculite aid by hydrogen ions.

It is evident from Fig. 3 that sodium, potassium or ammonium ion exchange lowered the exfoliation onset temperature of vermiculite to temperatures below $300{ }^{\circ} \mathrm{C}$. Among these, Navermiculite showed a comparably better expansion ratio. Mg-vermiculite showed a thermal behaviour similar to that of neat vermiculite (with the majority of magnesium ions as interlayer cations). This latter fact demonstrates the important contribution of the interlayer cations to the expansion behaviour of vermiculites.

In the increasing ionic potential series of $\mathrm{Na}-, \mathrm{Ba}-, \mathrm{Ca}-, \mathrm{Mg}$-vermiculite, the expansion onset temperature appears to increase dramatically. Hence these TMA results also provide evidence that cations with lower ionic potential (see Table 1) produce ion exchanged vermiculites with comparatively low expansion onset temperatures.

\section{$<$ Insert Fig. 3>}

The second step of $\mathrm{NH}_{4}$-vermiculite expansion occurs at slightly lower temperatures. This is also due to the release of ammonia and water resulting from the combination of hydrogen ions from ammonium ions and hydroxyl groups from the vermiculite surface. This is in agreement with previous study which also showed that the quantity of water released was 
more than expected from the dehydroxylation of vermiculite itself [43]. The stages involved in this process are demonstrated above in Schemes II, III and IV.

Rietveld quantitative analysis of blank vermiculite, i.e., neat vermiculite subjected to the same physical treatment as the other samples, showed the following mineralogical composition: Vermiculite: 15.88\%; Interstratified vermiculite/mica: 72.10\%; Mica (biotite and/or phlogopite): $6.13 \%$; Apatite: $2.73 \%$; Dolomite: $2.61 \%$.

$<$ Insert Fig. 4>

Fig. 4 shows XRD results of all samples. Mg-vermiculite showed similarities with the blank vermiculite. The main reflections were almost in the same positions and the main $\mathrm{Mg}$ vermiculite peak was present in both samples at ca. $2 \theta=6.17^{\circ}(1.43 \mathrm{~nm})$. However the blank vermiculite showed more well-defined interstratifications peaks, at $2 \theta=3.26^{\circ}(2.7 \mathrm{~nm}), 2 \theta=$ $7.13^{\circ}(1.24 \mathrm{~nm})$ and at $2 \theta=7.41^{\circ}(1.19 \mathrm{~nm})$, due to the presence of other interlayer cations (mainly K). This resemblance supports the fact that Palabora vermiculite is mainly Mg-type.

$<$ Insert Fig. 5>

In K-vermiculite, all typical vermiculite features had disappeared and the lattice had drastically collapsed [7]. By the same token, the typical well-ordered mica-like structure reflection at $2 \theta=8.74^{\circ}(10.10 \mathrm{~nm})$ was mostly observed (Fig. 4). Ca-vermiculite and Bavermiculite showed similar characteristics. The expected regular interstratification reflections at lower $2 \theta$ angles (long-spacing reflections) were not clearly observed, although it was seen that $\mathrm{K}^{+}$ions were still present in those samples. They both showed a distinctive and intense (002) reflection and a typical mica reflection at ca. $2 \theta=8.7^{\circ}(10.10 \mathrm{~nm})$. All samples, prepared with different salts, showed the typical $\mathrm{d}_{060}$ reflection at $1.53 \mathrm{~nm}$, confirming the maintenance of the trioctahedral mineral structure. 
A comparison of the XRD results of neat and blank vermiculites is presented in Fig. 5. It shows the effect of applying the shaker during vermiculite treatment. Blank vermiculite showed well-resolved reflexion peaks, especially at small $2 \theta$ angles, and no reflexion shift was observed. This result should be attributed to the effect of the washing and the removal of soluble impurities and small powdered vermiculite produced during milling, as well as the shaking processes.

Characteristic interstratified vermiculite reflection peaks were noticeable in both samples at $2 \theta=3.30^{\circ}(2.68 \mathrm{~nm})$ and $2 \theta=7.41^{\circ}(1.19 \mathrm{~nm})$. Typical $\mathrm{Mg}$-vermiculite and mica reflection peaks were located at $2 \theta=6.18^{\circ}(1.43 \mathrm{~nm})$ and $2 \theta=8.78^{\circ}(1.01 \mathrm{~nm})$, respectively.

All FT-IR spectra of the neat, alkali and alkaline metal exchanged vermiculites showed the structural $\mathrm{O}-\mathrm{H}$ group's stretching vibrations at $3709 \mathrm{~cm}^{-1}$. The $\mathrm{NH}_{4}$-vermiculite $\mathrm{O}-\mathrm{H}$ stretching vibrations was shifted to $3697 \mathrm{~cm}^{-1}$ since the position of this peak maximum is function of the nature of the interlayer cation [52-54].

$<$ Insert Fig. 6>

Characteristic vermiculite absorption bands were also observed in the results depicted in Fig. 6. Strong hydration $\mathrm{H}_{2} \mathrm{O}$ bands are noticeable at $3409-3424 \mathrm{~cm}^{-1}(\mathrm{O}-\mathrm{H}$ stretching vibrations and also bound silanol groups) and at 1638-1646 $\mathrm{cm}^{-1}(\mathrm{O}-\mathrm{H}$ bending vibrations) are noticeable [53-55]. Well defined $\mathrm{Si}-\mathrm{O}-\mathrm{Si}$ and $\mathrm{Si}-\mathrm{O}-\mathrm{Al}$ stretching vibrations are present at 996-997 $\mathrm{cm}^{-1}$, as well as a medium intensity band at ca. $456 \mathrm{~cm}^{-1}$ attributed to the Si-O-Mg structural bending vibration $[54,55]$. In addition, $\mathrm{NH}_{4}$-vermiculite presents bands at $3529 \mathrm{~cm}^{-}$ 1, $3283 \mathrm{~cm}^{-1}, 3064 \mathrm{~cm}^{-1}, 2835 \mathrm{~cm}^{-1}$ as well as a well-resolved band at $1430 \mathrm{~cm}^{-1}$ attributed to $\mathrm{NH}_{4}^{+}$vibration [22, 51, 56].

\section{Conclusions}


Modification of Palabora vermiculite was achieved by ion exchanging with ammonium and selected alkali metal and alkaline earth metal chlorides. All samples showed the typical $\mathrm{d}_{060}$ clay mineral reflexion at $1.53 \mathrm{~nm}$, confirming the maintenance of the trioctahedral structure. The thermal expansion of the neat vermiculite commenced at temperatures above $420{ }^{\circ} \mathrm{C}$ and reached levels exceeding an eight-fold expansion at ca. $700{ }^{\circ} \mathrm{C}$.

It was confirmed that the blowing agent was the interlayer water in the neat, alkali metal and alkaline earth metal ion exchanged vermiculite samples. In the ammonium ion exchanged vermiculite, it was found that ammonia and water were the blowing agents and that they were simultaneously released during thermal degradation. However, ammonium-vermiculite did not show a relatively better thermal expansion ratio, despite the presence of both ammonia and water in the interlayer.

Barium ions showed relatively high affinity to vermiculite surface. The ammonium ions were able to exchange potassium ions from biotite layers. Sodium, potassium and ammonium ion exchange lowered the exfoliation onset temperature to below $300{ }^{\circ} \mathrm{C}$. This means that the simple device of exchanging the interlayer magnesium ions with relatively low ionic potential aforementioned ions, lowered the exfoliation onset temperature to a range that may have technological significance, for instance in applications like intumescent fire barrier. 


\section{Acknowledgements}

Financial support for this research from the Institutional Research Development Programme (IRDP) and the South Africa/Mozambique Collaboration Programme of the National Research Foundation (NRF/FNI) is gratefully acknowledged.

\section{References}

[1] Grim, R.E. (1968). Clay Mineralogy, McGraw-Hill: New York, USA.

[2] Liu, Y., Xiao, D., Li, H. (2007). Separ. Sci. Technol., 42, 185.

[3] Bergaya, F., Theng, B.K.G., Lagaly, G. (Eds.) (2006). Handbook of Clay Science. Developments in Clay Science Series, Volume 1, Elsevier: Amsterdam, Netherlands.

[4] Annabi-Bergaya, F. (2008). Micropor. Mesopor. Mat., 107, 141.

[5] MacEwan, D.M.C., Ruiz-Amil, A., Brown, G. (1961). In: The X-ray identification and crystal structures of clay minerals, Brown, G. (Ed.), Mineralogical Society: London, 393.

[6] Basset, W.A. (1963). Clays and Clay Minerals $10^{\text {th }}$ Conference, Pergamon Press: New York, 61.

[7] Gast, R.G., Klobe, W.D., (1971). Clays Clay Miner., 19.

[9] Schoeman, J.J. (1989). J. S. Afr. Inst. Min. Metall., 89, 1.

[10] Frank, D., Edmond, L. (2001). United States Environmental Protection Agency: Seattle.

[11] Wada, T. (1973a). US Patent, 3753923.

[12] Wada, T. (1973b). US Patent, 3758415.

[13] Baumeister, W., Hahn, M. (1976). Micron, 7, 247.

[14] Langer, R.L., Marlor, A.J. (1981). US Patent, 4305992. 
[15] Muiambo, H.F., Focke, W.W., Atanasova, M., van der Westhuizen, I., Tiedt, L. (2010). Appl. Clay Sci., 50, 51.

[16] Walker, G.F. (1959). Nature 184, 1392.

[17] Harland, C.E. (1994). The Royal Society of Chemistry: Cambridge, UK.

[18] Tan, K.H. (1996). Marcel Dekker: New York.

[19] Thomas, J.Jr., Bohor, B.F. (1969). Clays Clay Miner., 17, 205.

[20] Couderc, P., Douillet, Ph. (1973). B. Soc. Fr. Ceram., 99, 51.

[21] Justo, A. (1989). Appl. Clay Sci., 4, 509.

[22] Stone, M.H., Wild, A. (1978). Clay Miner., 13, 337.

[23] Reichenbach, H.G., Beyer, J. (1997) Clay Miner., 29, 327.

[24] Justo, A., Pérez-Rodríguez, J.L., Sánchez-Soto, P.J. (1993). J. Thermal Anal., 40, 59.

[25] Ou, C., Bablouzian, L. (1994). US Patent, 5340643.

[26] Marcos, C., Argüelles, A., Ruiz-Conde, A., Sánchez-Soto, P.J., Blanco, J.A. (2003). Mineral. Mag., 67, 1253.

[27] Marcos, C., Arango, Y. C., Rodríguez, I. (2009). Appl. Clay Sci., 42, 368.

[28] Wild and Keay (1964). J. Soil Sci., 15, 135.

[29] Gier, S., Johns, W.D. (2000). App. Clay Sci., 16, 289.

[30] Badreddine, R., Vandormael, D., Fransolet, A.-M., Long, G.J., Stone, W.E.E., Grandjean, F. (2002). Clay Miner., 37, 367.

[31] Ferrage, E., Tournassat, C., Rinnert, E., Lanson, B. (2005). Geochim. Cosmochim. Ac., 69, 2797.

[32] Vidal, O., Dubacq, B. (2009). Geochim. Cosmochim. Ac., 73, 6544.

[33] Inoue, A. (1984). Clays Clay Miner., 32, 311.

[34] Barshad, I. (1950). Am. Mineral., 35, 225.

[35] Fripiat, J.J., Chaussidon, J., Touillaux, R. (1960). J. Phys. Chem-U.S., 64, 1234. 
[36] Harben, P.W., Roberts, R.L. (1990). Metal Bulletin Plc: London, UK.

[37] Kresten, P., Berggren, G. (1978). Thermochim. Acta, 23, 171.

[38] Okhotnikov, V.B., Babicheva, I.P., Musicantov, A.V., Aleksandrova, T.N. (1989). React. Solid., 7, 273.

[39] Evans, A.M. (1993). Blackwell Scientific Publications: Oxford.

[40] Tomanec, R., Popov, S., Vučinič, D., Lazič, P. (1997). Fizykochemiczne Problemy Mineralurgii, 31, 247.

[41] Obut, A., Girgin, I. (2002). Miner. Eng., 15, 683.

[42] Konta, J. (1995). Appl. Clay Sci., 10, 275.

[43] Pérez-Maqueda, L.A., Poyato, J., Pérez-Rodriquez, J. L. (2004). J. Thermal Anal. Cal., 78,375 .

[44] Skipper, N.T., Soper, A.K., McConnell, D.C. (1991). J. Chem. Phys., 94, 5751.

[45] Kodama, T., Komarneni, S. (1999). J. Mater. Chem., 9, 2475.

[46] Cardille, C.M., Slade, P.G. (1987). Clays Clay Miner., 35, 203.

[47] Marcos, C., Rodríguez, I. (2010). Appl. Clay Sci., 48, 492.

[48] Del Rey-Perez-Caballero, F.J., Poncelet, G. (2000). Micropor. Mesopor. Mat., 37, 313. [49] Shahwan, T., Erten, H.N. (2004). J. Radioanal. Nucl. Ch., 260, 43.

[50] Gabbott, P. (Ed), 2008. Principles and Applications of Thermal Analysis. Blackwell: Oxford, UK.

[51] Pérez-Rodríguez, J.L., Poyato, J., de Haro, M.C.J., Pérez-Maqueda, L.A., Lerf, A. (2004). Phys. Chem. Minerals, 31, 415.

[52] Bradley, W.F., Serratosa, J.M. (1960). Clays Clay Miner., 7, 260.

[53] Hougardy, J., Serratosa, J.M., Stone, W., van Olphen, H. (1970). Spec. Discuss. Faraday Soc., 1, 187. 
[54] Farmer, V.C. (1974). The infrared spectra of minerals, Mineralogical Society: London, UK.

[55] van der Marel, H.W., Beutelspacher, H. (1976). Atlas of infrared spectroscopy of clay minerals and their admixtures, Elsevier: Amsterdam, Netherlands.

[56] Petit, S., Righi, D., Madejová, J. (2006). App. Clay Sci., 34, 22.

\section{Table Captions}

Table 1: Dehydrated and hydrated ionic radii and respective calculated ionic potentials [1].

Table 2: XRF composition analysis of ammonium, alkali metal and alkaline earth metal ion exchanged vermiculite samples.

\section{Figure Captions}

Fig. 1: TG plots of ion exchanged vermiculites.

Fig. 2: Mass loss of ion exchanged vermiculites.

Fig. 3: TMA expansion of ion exchanged vermiculites.

Fig. 4: XRD patterns of blank, alkali metal and alkaline metal treated vermiculites.

Fig. 5: XRD patterns of neat vermiculite and blank vermiculite.

Fig. 6: FT-IR spectra of neat vermiculite, ammonium, alkali metal and alkaline metal ion exchanged vermiculites. 
Table 1: Dehydrated and hydrated ionic radii and respective calculated ionic potentials [1].

\begin{tabular}{cccc}
\hline Ion & $\begin{array}{c}\text { Dehydrated ionic } \\
\text { radius }\left(\mathbf{z}_{\mathbf{d}}, \mathbf{n m}\right)\end{array}$ & $\begin{array}{c}\text { Hydrated ionic } \\
\text { radius }\left(\mathbf{z}_{\mathbf{h}}, \mathbf{n m}\right)\end{array}$ & $\begin{array}{c}\text { Ionic potential } \\
\left(\mathbf{z}_{\mathbf{d}} / \mathbf{r}\right)\end{array}$ \\
\hline $\mathrm{NH}_{4}^{+}$ & 0.143 & 0.537 & 7.0 \\
$\mathrm{~K}^{+}$ & 0.133 & 0.380 & 7.5 \\
$\mathrm{Na}^{+}$ & 0.098 & 0.560 & 10.2 \\
$\mathrm{Mg}^{2+}$ & 0.078 & 1.080 & 25.6 \\
$\mathrm{Ca}^{2+}$ & 0.106 & 0.960 & 18.9 \\
$\mathrm{Ba}^{2+}$ & 0.143 & 0.880 & 14.0 \\
\hline
\end{tabular}


Table 2: XRF composition analysis of ammonium, alkali metal and alkaline earth metal ion exchanged vermiculite samples.

\begin{tabular}{|c|c|c|c|c|c|c|}
\hline Sample & Na- & K- & Mg- & Ca- & Ba- & $\mathbf{N H}_{4-}$ \\
\hline $\mathrm{SiO}_{2}$ & 38.76 & 35.64 & 39.54 & 39.45 & 39.38 & 40.29 \\
\hline $\mathrm{MgO}$ & 23.42 & 23.81 & 24.21 & 22.44 & 22.49 & 22.74 \\
\hline $\mathrm{Al}_{2} \mathrm{O}_{3}$ & 9.47 & 9.24 & 10.16 & 9.60 & 9.69 & 10.11 \\
\hline $\mathrm{Fe}_{2} \mathrm{O}_{3}$ & 8.27 & 10.09 & 8.12 & 8.17 & 8.24 & 8.21 \\
\hline $\mathrm{CaO}$ & 3.87 & 5.40 & 3.42 & 5.06 & 3.40 & 3.76 \\
\hline $\mathrm{K}_{2} \mathrm{O}$ & 5.10 & 6.77 & 5.07 & 5.36 & 4.89 & 5.18 \\
\hline $\mathrm{P}_{2} \mathrm{O}_{5}$ & 0.88 & 1.19 & 1.17 & 0.98 & 1.12 & 0.99 \\
\hline $\mathrm{Na}_{2} \mathrm{O}$ & 1.69 & $<0.01$ & $<0.01$ & $<0.01$ & $<0.01$ & $<0.01$ \\
\hline $\mathrm{TiO}_{2}$ & 0.94 & 1.10 & 1.05 & 1.00 & 1.02 & 1.01 \\
\hline $\mathrm{MnO}$ & 0.04 & 0.06 & 0.06 & 0.06 & 0.07 & 0.06 \\
\hline $\mathrm{Cr}_{2} \mathrm{O}_{3}$ & 0.03 & 0.03 & 0.03 & 0.03 & 0.04 & 0.04 \\
\hline $\mathrm{NiO}$ & 0.03 & 0.03 & 0.03 & 0.03 & 0.04 & 0.03 \\
\hline $\mathrm{V}_{2} \mathrm{O}_{5}$ & $<0.01$ & $<0.01$ & 0.01 & 0.02 & $<0.01$ & $<0.01$ \\
\hline $\mathrm{SO}_{3}$ & $<0.01$ & $<0.01$ & $<0.01$ & 0.04 & $<0.01$ & $<0.01$ \\
\hline $\mathrm{BaO}$ & $<0.01$ & $<0.01$ & $<0.01$ & $<0.01$ & 4.00 & $<0.01$ \\
\hline $\mathrm{Cl}$ & $<0.01$ & $<0.01$ & $<0.01$ & 0.03 & $<0.01$ & $<0.01$ \\
\hline $\mathrm{CuO}$ & 0.01 & 0.03 & 0.02 & 0.02 & 0.02 & 0.02 \\
\hline $\mathrm{ZnO}$ & 0.02 & $<0.01$ & 0.02 & 0.02 & 0.01 & 0.01 \\
\hline $\mathrm{Rb}_{2} \mathrm{O}$ & 0.05 & 0.09 & 0.05 & 0.05 & 0.04 & 0.05 \\
\hline $\mathrm{SrO}$ & 0.02 & 0.07 & 0.02 & 0.01 & 0.01 & 0.02 \\
\hline LOI & 7.39 & 6.43 & 7.02 & 7.64 & 5.50 & 7.49 \\
\hline Total & 100.00 & 100.00 & 100.00 & 100.00 & 100.00 & 100.00 \\
\hline
\end{tabular}




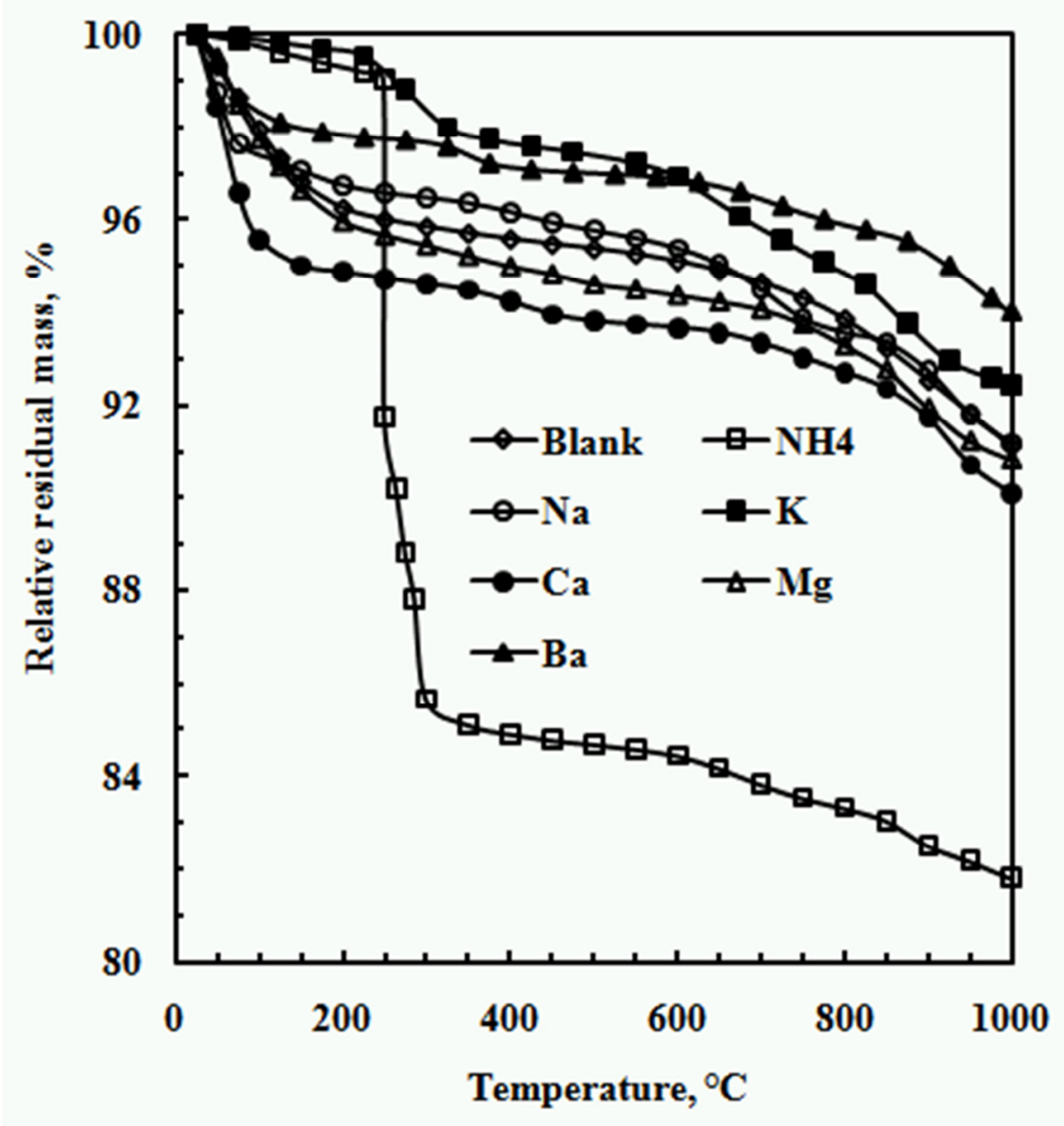

Fig. 1: TG plots of ion exchanged vermiculites. 


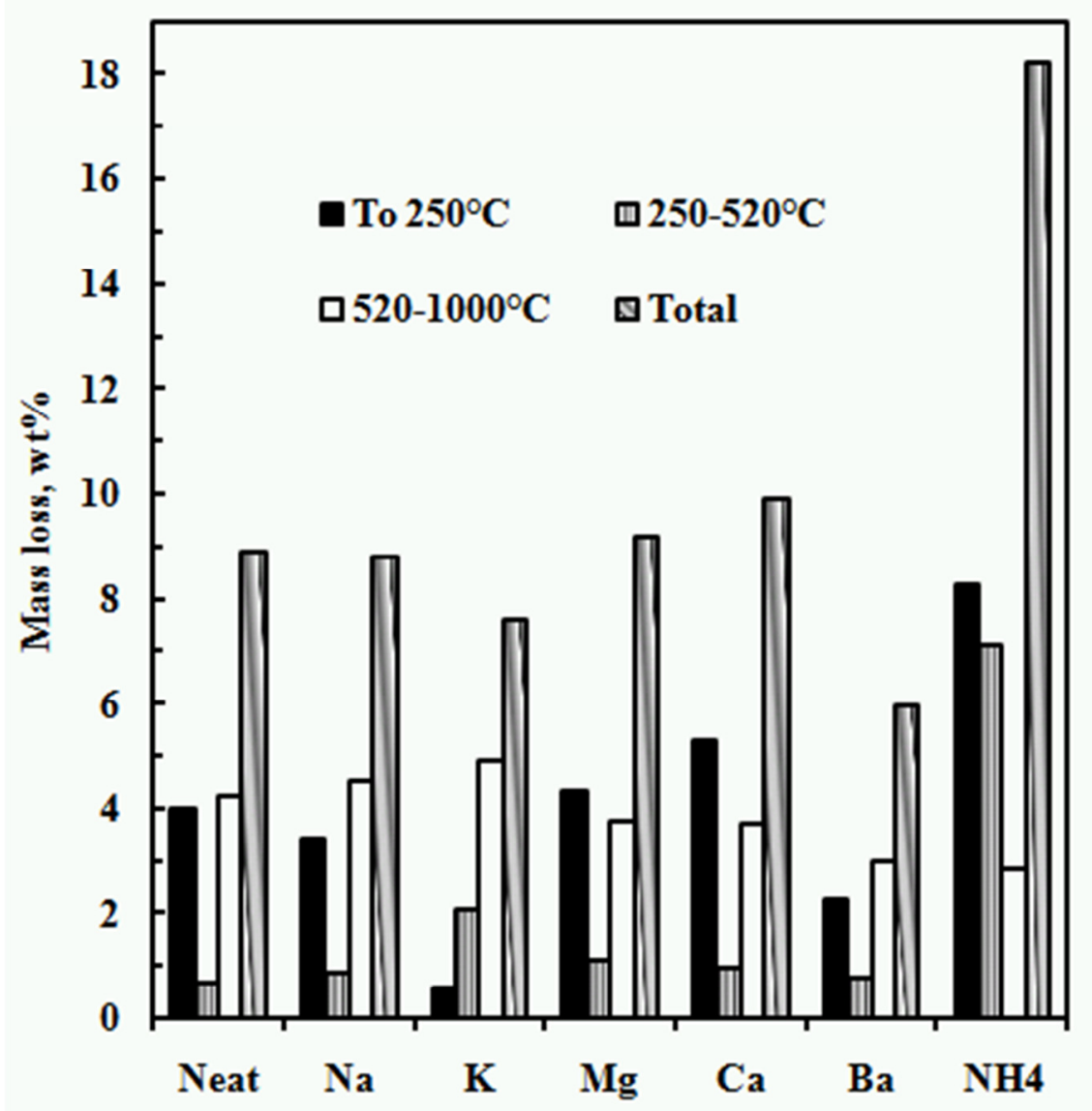

Fig. 2: Mass loss of ion exchanged vermiculites. 




Fig. 3: TMA expansion of ion exchanged vermiculites. 


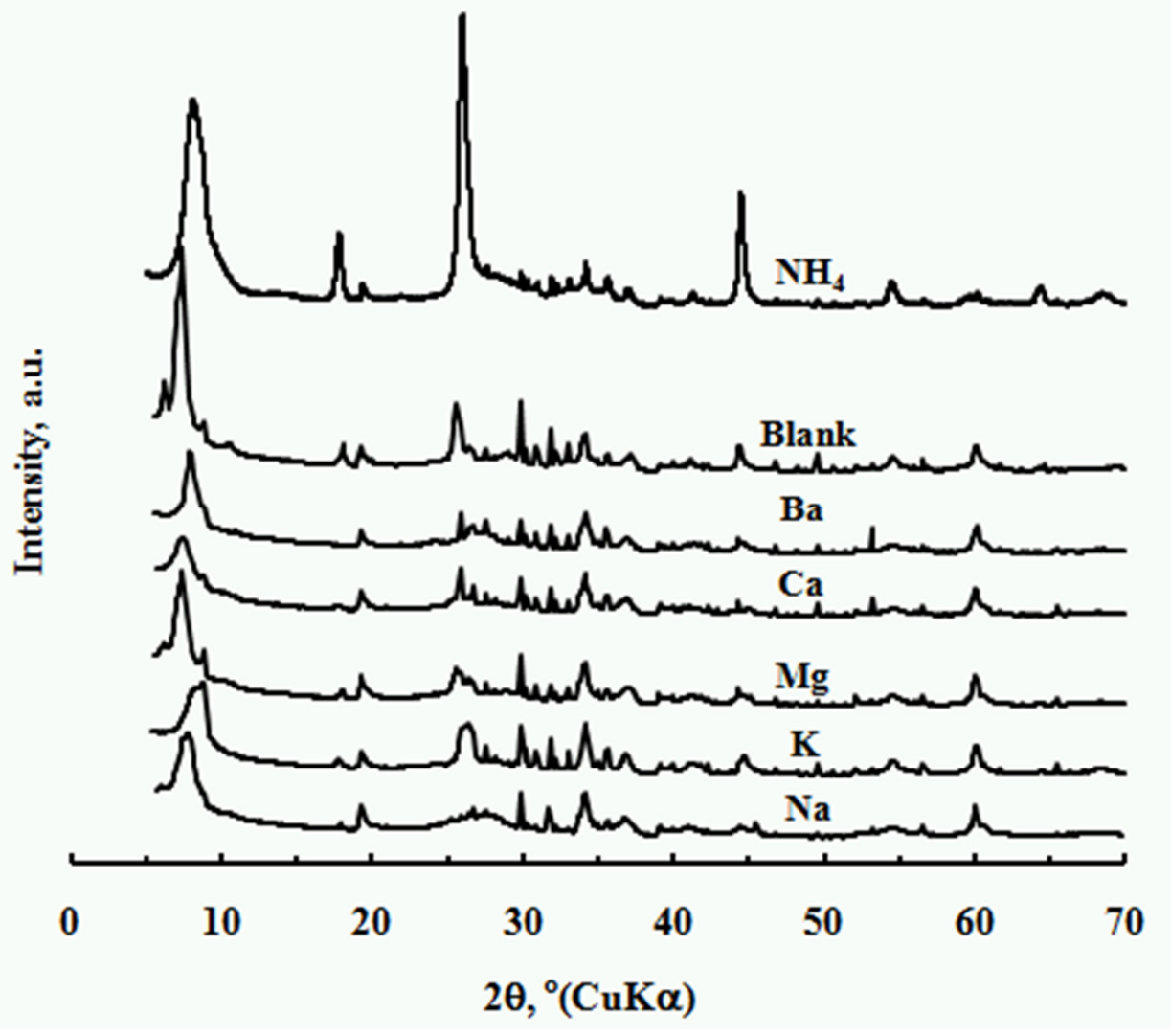

Fig. 4: XRD patterns of blank, alkali metal and alkaline metal treated vermiculites. 


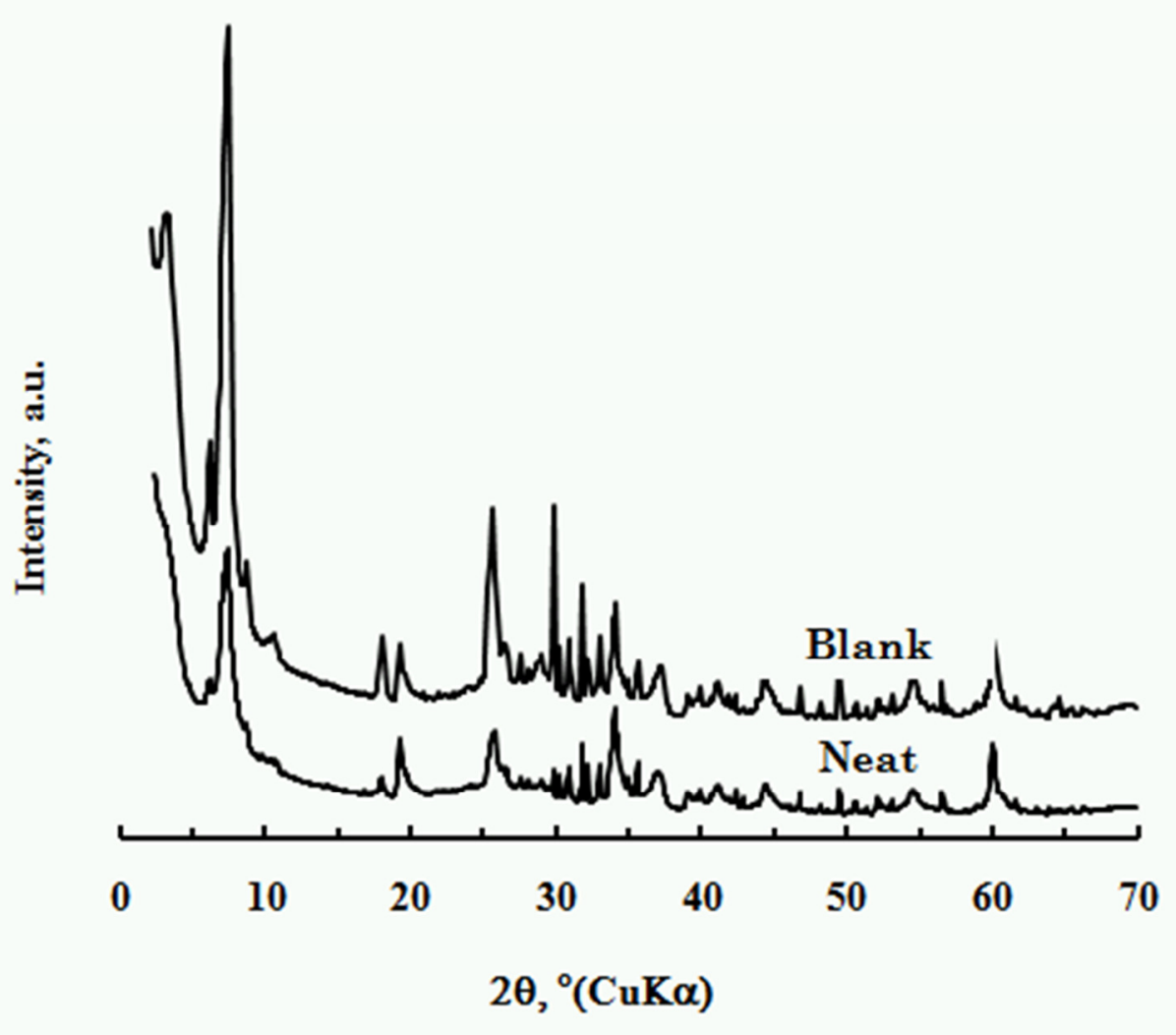

Fig. 5: XRD patterns of neat vermiculite and blank vermiculite. 


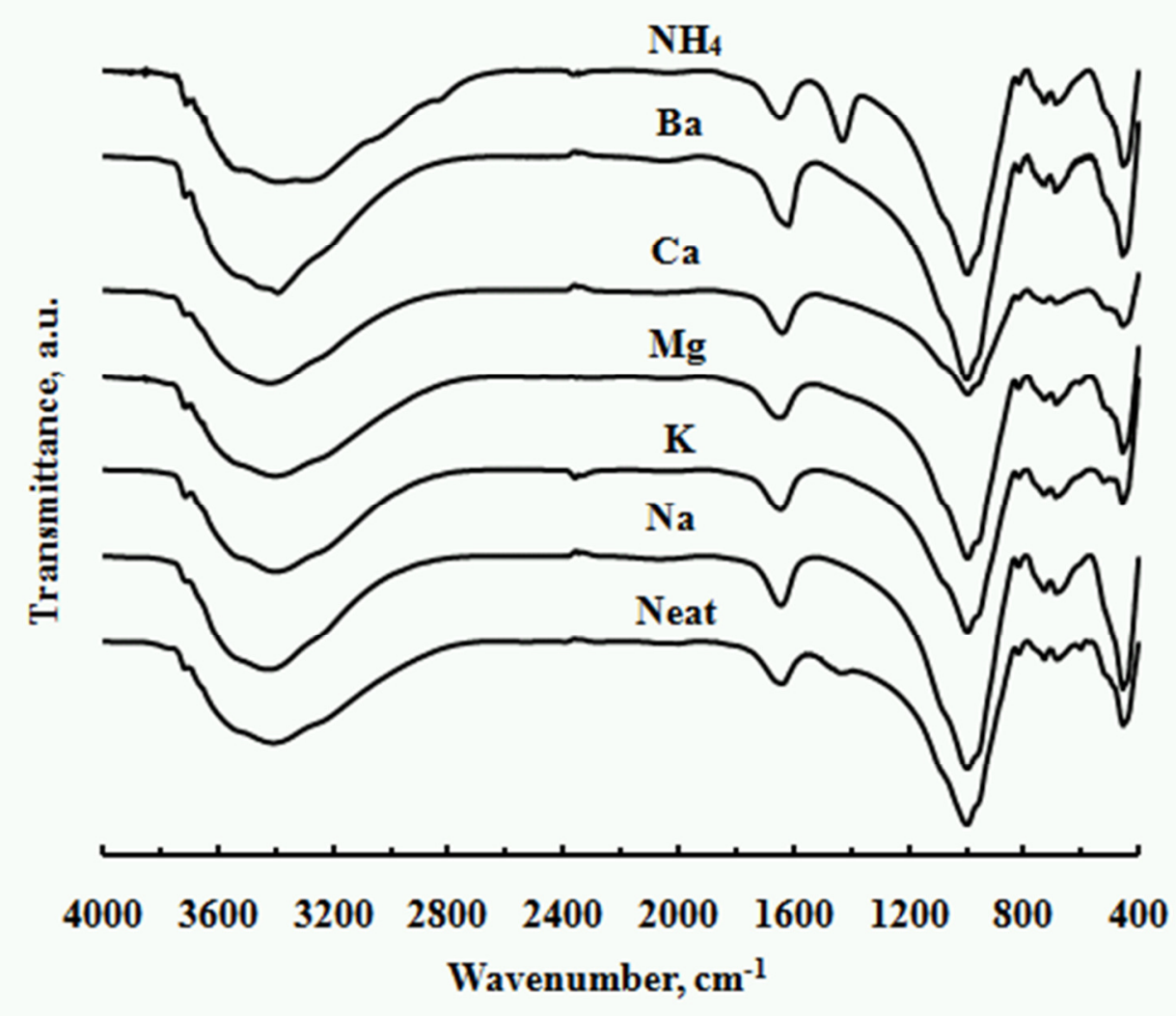

Fig. 6: FT-IR spectra of neat vermiculite, ammonium, alkali metal and alkaline metal ion exchanged vermiculites. 